\title{
Characteristics of Electrical Contact of Internally Oxidized Silver-Zinc Alloys Containing Several Additional Elements*
}

\author{
By Mitsunori Sato** and Masayuki Hijikata**
}

\begin{abstract}
$\mathrm{Ag}-2-10$ at $\% \mathrm{Zn}$ alloys containing small amounts of several additional elements such as 1 at $\%$ Sn, 1 at $\%$ In, 0.5 at $\% \mathrm{Te}, 0.5-3$ at $\% \mathrm{Cu}$ and 0.5 at $\% \mathrm{Li}$ were internally oxidized in air, and in oxygen of 0.1 and $0.5 \mathrm{MPa}$ at 1073 and $1123 \mathrm{~K}$. The characteristics of electrical contact, such as welding adhesion, erosion and contact resistance of the alloys were investigated.

(1) Internally oxidized $\mathrm{Ag}-8-10 \mathrm{Zn}-0.5 \mathrm{Te}, \mathrm{Ag}-6 \mathrm{Zn}-1 \mathrm{Sn}-0.5 \mathrm{Te}$ and $\mathrm{Ag}-4-6 \mathrm{Zn}-1 \mathrm{Sn}-1 \mathrm{In}-0.5 \mathrm{Te}$ alloys are superior as electrical contacts. (2) The welding adhesion is affected by both the oxide content and the dispersed structure. On the other hand, the erosion is affected by the oxide content, but not by the dispersed structure. (3) The contact resistance increases with increasing oxide content, as well as with the addition of $\mathrm{Sn}$ and In.
\end{abstract}

(Received December 14, 1981)

\section{Introduction}

Internally oxidized alloys in which various oxide particles disperse in the silver matrix are used extensively as electrical contact materials $^{(1)-(15)}$, Ag-Cd oxide contacts being typical ones ${ }^{(1)-(5)}$. As $\mathrm{Cd}$ is harmful to the human body, the development of alternative contact materials is required recently ${ }^{(9)-(15)}$. Silver-oxide contacts should have high resistance to welding adhesion, high resistance to erosion, low contact resistance and high resistance to reignition. These characteristics are strongly dependent on both the kind of containing oxides and the structure of the oxide particles dispersed ${ }^{(2)(6)-(8)(10)(12)-(16)}$. The oxides dispersed are necessary to have some characteristics as follows: (1) Alloying elements have wide solubility range with Ag before internal oxidation. (2) The oxide particles of the alloying elements are formed in a wide concentration range by the internal oxidation process. (3) The oxides have sufficiently small affinity with $\mathrm{Ag}$ and do not react each other; (4) they are insoluble in water and sufficiently little hygroscopic; (5) they have high vapor

* This paper was originally published in Japanese in J. Japan Inst. Metals, 44 (1980), 569.

** National Research Institute for Metals, 2-1 Sengen-1, Sakura-mura, Niihari-gun, Ibaraki 305, Japan. pressure, and they are easily sublimated as a migrated oxide layer does not deposit on a contact surface; and (6) they have low melting temperature or low sublimate temperature as a reignition occurs easily with the increase in a thermionic emission. The oxides of $\mathrm{Cd}, \mathrm{Zn}, \mathrm{Sn}$, In and Te satisfy such characteristics ${ }^{(16)}$. The internally oxidized alloys in which these oxides are uniformly dispersed in the silver matrix are expected to have superior characteristics of electrical contacts. However, in the internally oxidized specimens of the binary alloys of $\mathrm{Ag}$ with one of these elements besides $\mathrm{Cd}$, the oxides are formed in a laminated structure or are precipitated in a grain boundary, and, therefore, it is difficult to obtain the dispersed structure of oxide particles in a wide concentration range ${ }^{(8)(10)(12)(15)}$.

In a previous paper ${ }^{(17)}$, for internally oxidized $\mathrm{Ag}-\mathrm{Zn}$ alloys containing small amounts of several additional elements such as $\mathrm{Sn}, \mathrm{In}, \mathrm{Te}, \mathrm{Cu}$ and $\mathrm{Li}$, we investigated the effects of the composition, the internal oxidation temperature and the oxygen pressure of atmosphere on the microstructures of the internally oxidized layers. Results obtained are as follows: (1) The concentration range, in which oxide particles are uniformly dispersed in the silver matrix, was estimated for internally oxidized Ag-Zn-Te, Ag-Zn-Sn-Te, Ag-ZnIn-Te and Ag-Zn-Sn-In-Te alloys. (2) An addition of $\mathrm{Te}$ disperses oxide particles uni- 
formly, leading to a wide concentration range in which the internal oxidation proceeds. (3) A replacement of $\mathrm{Te}$ by $\mathrm{Cu}$ or $\mathrm{Li}$ has a similar effect on the dispersion of oxide particles to the addition of Te. (4) An addition of $\mathrm{Sn}$ results in a fine oxide particle size.

In the present work we have prepared the $\mathrm{Ag}-\mathrm{Zn}$ alloys containing small amounts of several additional elements such as $\mathrm{Sn}$, In, $\mathrm{Te}, \mathrm{Cu}$ and $\mathrm{Li}$ in the concentration range in which the oxide particles are uniformly dispersed in the silver matrix by internal oxidation. The oxide particle size is controlled by the internal oxidation temperature and the oxygen pressure of atmosphere. The characteristics of electrical contacts such as welding adhesion, erosion and contact resistance of the alloys are investigated.

\section{Experimental}

\section{Specimens}

Table 1 shows the chemical composition of specimens prepared from $\mathrm{Ag}$ of $99.9 \%, \mathrm{Zn}$ of $99.8 \%$, Sn of $99.9 \%$, In of $99.999 \%$, Te of $99.99 \%, \mathrm{Cu}$ of $99.9 \%, \mathrm{Li}$ of $99 \%, \mathrm{Cd}$ of $99.9 \%$ and $\mathrm{Ni}$ of $99.9 \%$. Contact pieces were made in a disk $10 \mathrm{~mm}$ in diameter with a spherical surface $30 \mathrm{~mm}$ in radius of curvature, and were internally oxidized in air and in oxygen of 0.1 and $0.5 \mathrm{MPa}$ at 1073 and $1123 \mathrm{~K}$. The microstructures of internally oxidized layers of the alloys were observed using an optical microscope.

\section{Procedures}

The welding force was measured with a balance system test apparatus. Testing current was supplied from a capacitor of $7.88 \mathrm{mF}$ charged up to $300 \mathrm{~V}$ under a contact force of $2 \mathrm{~N}$. When the making arc discharge occurs, the current was decreased from the maximum value of $2460 \mathrm{~A}$ with a time constant of 0.96 $\mathrm{ms}$, and in this case, the arc discharge from 2 to $3 \mathrm{~ms}$ occurs to bounce by electromagnetic repulse force. On the other hand, when the making arc does not occur, the current was

Table 1 Chemical composition of specimens (at $\%$ ).

\begin{tabular}{|c|c|c|c|c|c|c|c|c|c|}
\hline Specimen & $\mathrm{Zn}$ & Sn & In & $\mathrm{Te}$ & $\mathrm{Cu}$ & $\mathrm{Li}$ & $\mathrm{Ag}$ & $\mathrm{Cd}$ & $\mathrm{Ni}$ \\
\hline $200 \mathrm{~T}$ & 2.15 & - & - & 0.52 & - & - & Bal & - & - \\
\hline $400 \mathrm{~T}$ & 4.23 & - & - & 0.50 & - & - & " & - & - \\
\hline $600 \mathrm{~T}$ & 6.04 & - & - & 0.49 & - & - & " & - & - \\
\hline $800 \mathrm{~T}$ & 7.62 & - & - & 0.45 & - & - & " & - & - \\
\hline $1000 \mathrm{~T}$ & 9.78 & - & - & 0.49 & - & - & " & - & - \\
\hline $201 \mathrm{~T}$ & 2.15 & - & 1.02 & 0.50 & - & - & " & - & - \\
\hline $401 \mathrm{~T}$ & 4.18 & - & 1.17 & 0.49 & - & - & " & - & - \\
\hline $601 T$ & 6.01 & - & 1.02 & 0.50 & - & - & " & $\cdot$ & - \\
\hline $210 \mathrm{~T}$ & 2.14 & 0.93 & - & 0.50 & - & - & " & - & - \\
\hline $410 \mathrm{~T}$ & 4.07 & 0.94 & - & 0.49 & - & - & " & - & - \\
\hline $610 \mathrm{~T}$ & 6.13 & 0.97 & - & 0.48 & - & - & " & - & - \\
\hline $211 \mathrm{~T}$ & 2.15 & 1.14 & 1.00 & 0.50 & - & - & " & - & - \\
\hline $411 T$ & 3.73 & 1.01 & 1.07 & 0.46 & - & - & " & - & - \\
\hline $611 \mathrm{~T}$ & 6.05 & 1.03 & 0.99 & 0.47 & - & - & " & - & - \\
\hline $410 \mathrm{C}$ & 3.93 & 0.99 & - & - & 0.45 & - & " & - & - \\
\hline $410 \mathrm{C} 1$ & 3.92 & 0.97 & - & - & 0.93 & - & " & - & - \\
\hline $410 \mathrm{C} 2$ & 3.92 & 1.00 & - & - & 1.89 & - & " & - & - \\
\hline $410 \mathrm{C} 3$ & 3.84 & 0.97 & - & - & 2.79 & - & " & - & - \\
\hline $411 \mathrm{C}$ & 4.04 & 1.08 & 1.01 & - & 0.50 & - & " & - & - \\
\hline $410 \mathrm{~L}$ & 3.62 & 0.98 & - & - & - & 0.45 & " & - & - \\
\hline $610 \mathrm{~L}$ & 5.89 & 1.02 & - & - & - & 0.46 & " & - & - \\
\hline $411 \mathrm{~L}$ & 3.99 & 1.07 & 1.00 & - & - & 0.46 & $"$ & - & - \\
\hline $\mathrm{Ag}$ & - & - & - & - & - & - & 99.9 & - & - \\
\hline $\mathrm{CdO}$ & - & - & - & - & - & - & Bal & 11.3 & - \\
\hline CdON & - & - & - & - & - & - & " & 11.4 & 0.24 \\
\hline
\end{tabular}


decreased from the maximum value of $1350 \mathrm{~A}$ with a time constant of $1.75 \mathrm{~ms}$. The resistance to welding adhesion was defined from a welding force in each operation and a sum of them in 20 operations. After the operations the surface patterns of the contacts were observed with a scanning electron microscope. The wave forms of contact voltage and current were observed by means of an oscilloscope. The measurements of erosion loss and contact resistance were made with a switching test apparatus ${ }^{(2)}$, which had a closing and separating speed of 63 $\mathrm{mms}^{-1}$, a frequency of $2 \mathrm{~s}^{-1}$, a making force of $2 \mathrm{~N}$, and a breaking force of $3 \mathrm{~N}$. The circuit conditions are an applied voltage of a.c. $100 \mathrm{~V}$, a current of $115 \mathrm{~A}$ and a power factor $(\cos \phi)$ of 0.3 , and an applied voltage of $200 \mathrm{~V}$, a current of $90 \mathrm{~A}$ and a power factor of 0.28 . The amount of erosion was weighed after $3 \times 10^{4}$ operations with a microbalance having an accuracy of $10^{-9} \mathrm{~kg}$, and was plotted in figures by the medium values in the tests of three times. The contact resistance was calculated from ten times measurements of the contact voltage and current after about $3 \times 10^{4}$ operations.

\section{Reuslts and Discussion}

\section{Microstructures of internally oxidized specimens}

Photograph 1 shows the typical microstructures of the specimens internally oxidized in oxygen of $0.1 \mathrm{MPa}$ at $1123 \mathrm{~K}$. The microstructures for all specimens can be classified in the following groups; $\mathrm{Ag}-\mathrm{Zn}-\mathrm{Te}$ alloys having a similar microstructure as shown in (a), $\mathrm{Ag}_{-}$ $\mathrm{Zn}-\mathrm{In}-\mathrm{Te}$ alloys as shown in (b), $\mathrm{Ag}-\mathrm{Zn}-\mathrm{Sn}-$ Te alloys as shown in (c), $\mathrm{Ag}-\mathrm{Zn}-\mathrm{Sn}-\mathrm{In}-\mathrm{Te}$ alloys as shown in (d), $\mathrm{Ag}-\mathrm{Zn}-\mathrm{Sn}-\mathrm{Cu}$ alloys and $\mathrm{Ag}-\mathrm{Zn}-\mathrm{Sn}-\mathrm{In}-\mathrm{Cu}$ alloys as shown in (e), and $\mathrm{Ag}-\mathrm{Zn}-\mathrm{Sn}-\mathrm{Li}$ alloys and $\mathrm{Ag}-\mathrm{Zn}-\mathrm{Sn}-\mathrm{In}-\mathrm{Li}$ alloys as shown in (f). Photograph 2 shows the microstructures of the specimens $800 \mathrm{~T}$ and $611 \mathrm{~T}$ internally oxidized in oxygen of $0.1 \mathrm{MPa}$ at $1073 \mathrm{~K}$. When Photo. 1 (a) and (d) at $1123 \mathrm{~K}$ are compared with Photo. 2(a) and (b) at
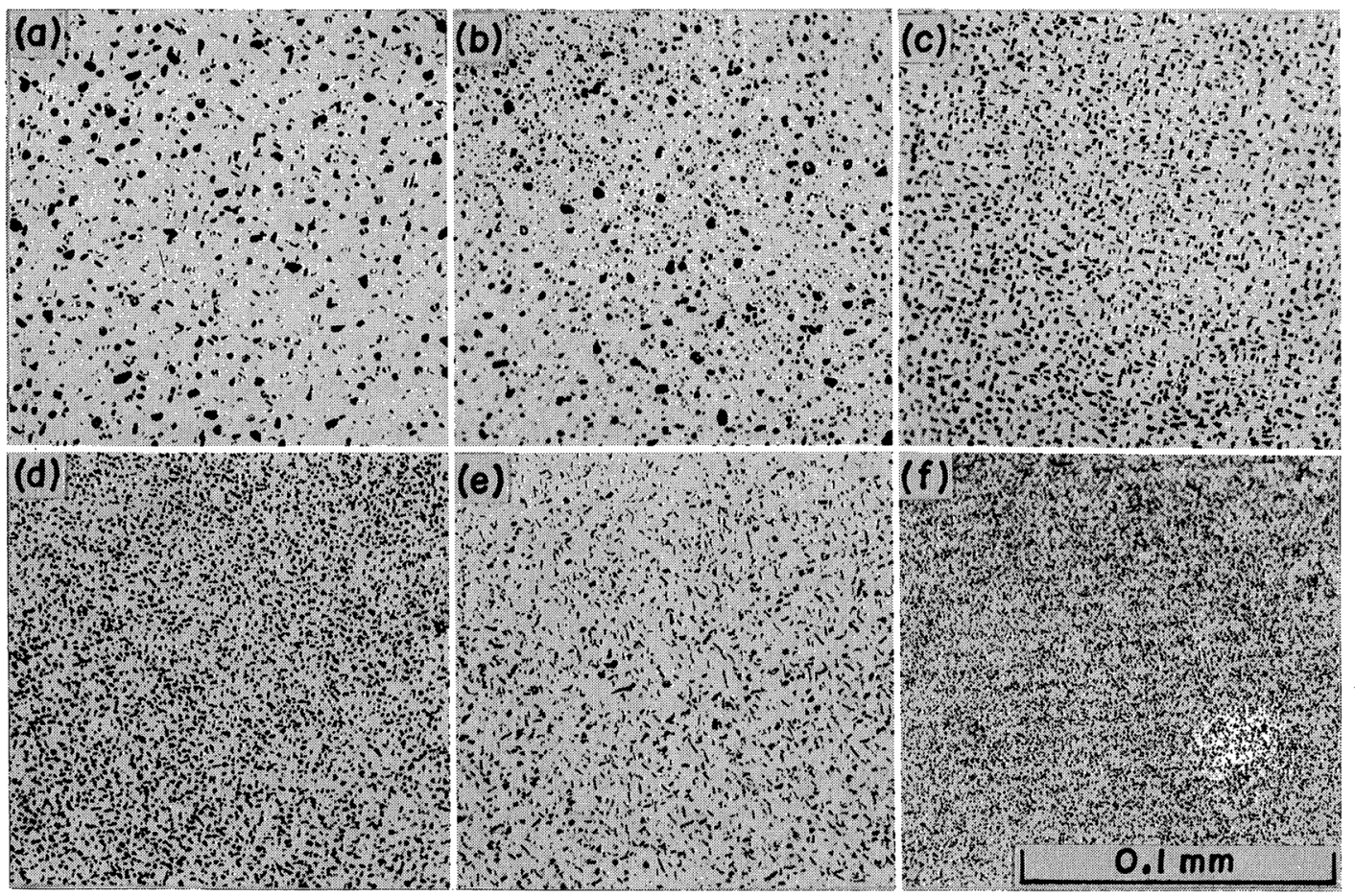

Photo. 1 Microstructures of specimens internally oxidized in oxygen of $0.1 \mathrm{MPa}$ at $1123 \mathrm{~K}$. (a) $800 \mathrm{~T}$, (b) 601T, (c) 610T, (d) 611T, (e) 410C, and (f) 610L. 


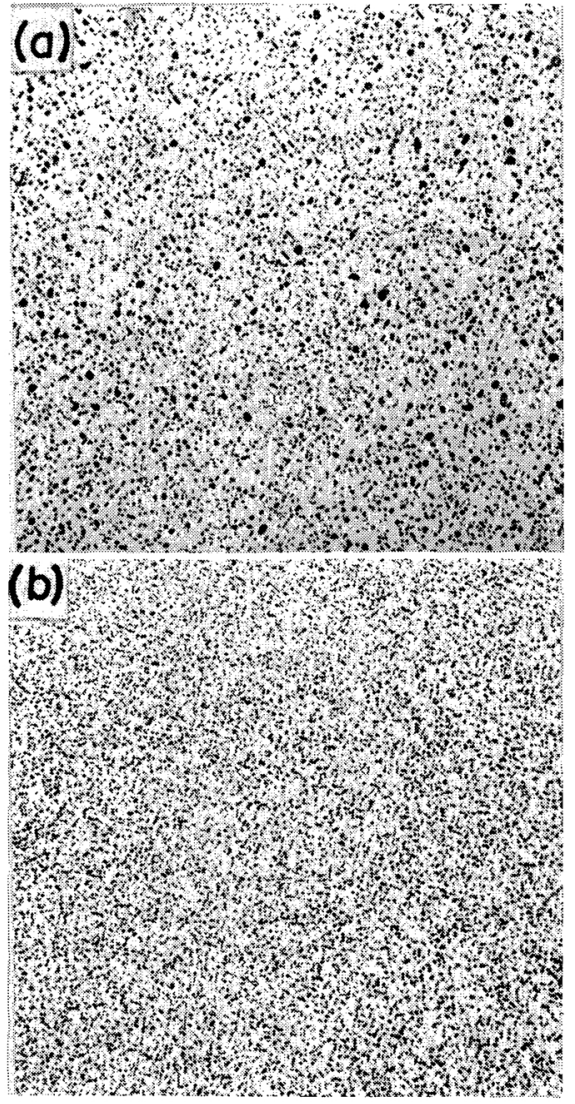

Photo. 2 Microstructures of the specimens (a) 800T and (b) 611T internally oxidized in oxygen of $0.1 \mathrm{MPa}$ at $1073 \mathrm{~K}$.

$1073 \mathrm{~K}$ respectively, oxide particles are found to be finer at lower temperatures.

\section{Welding adhesion}

A switching apparatus having Ag-oxide contacts must have high resistance to welding adhesion. For Ag-oxide contacts different resistances to welding adhesion have been often obtained for different testing conditions ${ }^{(18)-(20)}$. We have paid attention to the resistance in two cases; (1) in one case arc discharge at contact making occurs and (2) in the other it does not occur. When the arc discharge occurs, the transient wave forms of voltage, e, and current, $i$, are as shown in Photo. 3. For Ag contacts as shown in (a) the arc voltage is found to oscillate ${ }^{(21)(22)}$, but for the present specimens the arc voltage is lower and hardly oscil-

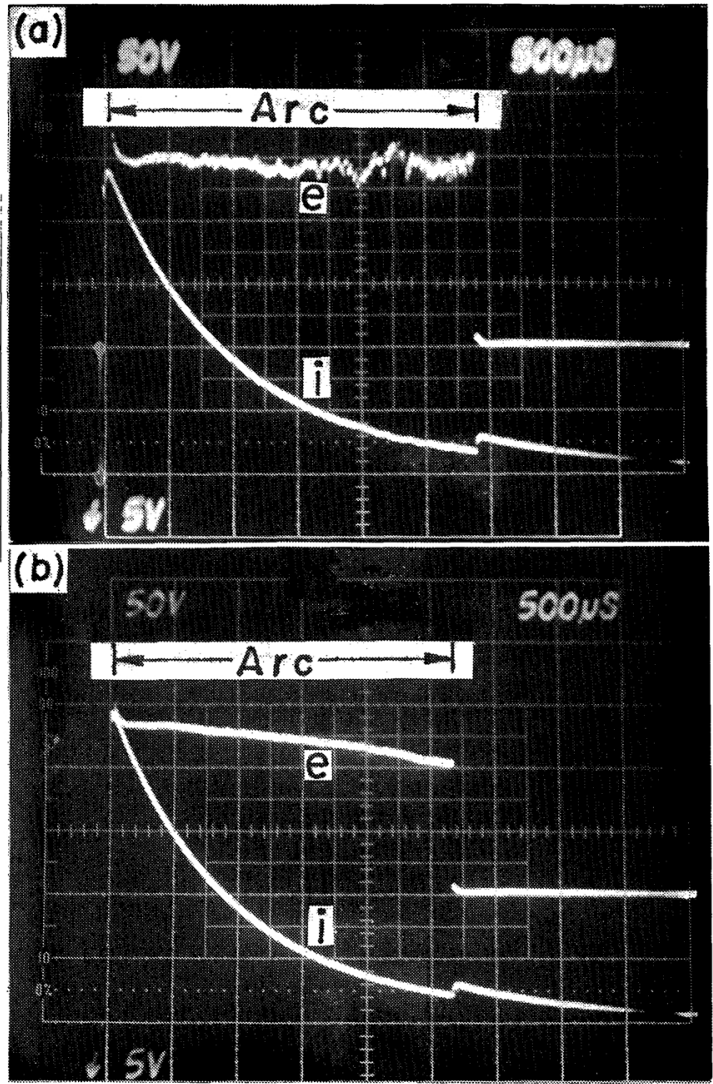

Photo. 3 Oscillograms of contact voltage, $e$, and current, $i$, for specimens (a) $\mathrm{Ag}$ and (b) 611T internally oxidized in oxygen of $0.1 \mathrm{MPa}$ at $1073 \mathrm{~K}$. Maximum current is $2460 \mathrm{~A}$ and time constant is $0.96 \mathrm{~ms}$.

lates as shown in (b). For the Ag contacts which belong to a T-F emission type ${ }^{(23)}$, the cathode drop voltage drifts with moving the cathode spot in arc discharge, and therefore, the arc voltage oscillates. On the other hand, for the Ag-oxide contacts the electron emission occurs easily in the neighborhood of the oxide particles dispersed in the silver matrix, and therefore, the cathode drop voltage does not drift and the arc voltage may be stable ${ }^{(24)(25)}$. When the arc discharge does not occur, the transient wave forms of contact voltage, e, and current, $i$, are shown in Photo. 4.

\section{(1) The case in which the arc discharge occurs}

Silver-oxide contacts are extensively used 


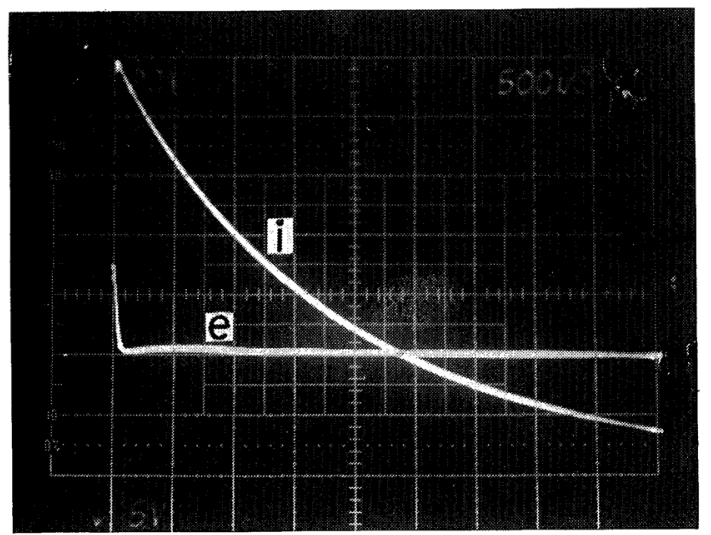

Photo. 4 Oscillogram of contact voltage, $e$, and current, $i$, for specimen Ag. Maximum current is $1350 \mathrm{~A}$ and time constant is $1.75 \mathrm{~ms}$.

in cases in which switching arc occurs. Figure 1 shows the welding adhesion behavior for some Te addition specimens having the uniformly dispersed oxide particles; $\mathrm{Ag}-\mathrm{Zn}-\mathrm{Te}$ alloys in (a), Ag-Zn-In-Te alloys in (b), Ag$\mathrm{Zn}-\mathrm{Sn}-\mathrm{Te}$ alloys in (c) and $\mathrm{Ag}-\mathrm{Zn}-\mathrm{Sn}-\mathrm{In}-\mathrm{Te}$ alloys in (d) were internally oxidized in oxygen of $0.1 \mathrm{MPa}$ at 1073 and $1123 \mathrm{~K}$. The resistance to welding adhesion is improved with increasing oxide content for all specimens. The specimens internally oxidized at $1073 \mathrm{~K}$ have higher resistance to welding adhesion than those at $1123 \mathrm{~K}$. As the oxide particle size becomes finer the resistance to welding adhesion is generally improved. For the $\mathrm{Ag}-\mathrm{Zn}-\mathrm{Te}$ alloys $800 \mathrm{~T}$ and $1000 \mathrm{~T}$, the oxide particle size is coarser than the other specimens as shown in Photo. 1 (a) and Photo. 2(a). If the oxide particle size becomes finer by internal oxidation at lower temperature, the resistance to welding adhesion may be more improved. However, for the $\mathrm{Ag}-\mathrm{Zn}-\mathrm{Te}$ alloy 200T and $\mathrm{Ag}-\mathrm{Zn}$-Sn-Te alloy $210 \mathrm{~T}$ with low concentration of additional elements, the oxide particle size in the specimens internally oxidized at $1123 \mathrm{~K}$ is coarser than that at $1073 \mathrm{~K}$ and have higher resistance to welding adhesion. These results may arise from the fact that when the internal oxidation temperature is the same, the oxide particle size becomes finer with decreasing concentration and that the most suitable dispersed structure exists for each composition. Moreover, the additions of Sn or Sn and In are effective to improve the resistance to welding adhesion.

Figure 2 shows the welding adhesion behavior for the specimens in which Te was replaced by $\mathrm{Cu}$ or $\mathrm{Li}$; the $\mathrm{Ag}-\mathrm{Zn}-\mathrm{Sn}-\mathrm{Cu}$ and $\mathrm{Ag}-\mathrm{Zn}-\mathrm{Sn}-$ $\mathrm{Li}$ alloys in (a) and the $\mathrm{Ag}-\mathrm{Zn}-\mathrm{Sn}-\mathrm{In}-\mathrm{Cu}$ and $\mathrm{Ag}-\mathrm{Zn}-\mathrm{Sn}-\mathrm{In}-\mathrm{Li}$ alloys in (b) were internally oxidized in oxygen of $0.1 \mathrm{MPa}$ at 1073 and $1123 \mathrm{~K}$. For the $\mathrm{Cu}$ or $\mathrm{Li}$ addition specimens in which the oxide particles are dispersed, the resistance to welding adhesion is lower than that for the Te addition ones. A high magnitude of the welding adhesion frequently occurs in the specimens containing $\mathrm{Cu}$.

Figure 3 shows the welding adhesion behavior for the $\mathrm{Ag}-\mathrm{Zn}-\mathrm{Sn}-\mathrm{Cu}$ alloys with different $\mathrm{Cu}$ contents. The resistance to welding adhesion decreases with increasing $\mathrm{Cu}$ content.

Figure 4 shows the welding adhesion behavior on the contact surface after $3 \times 10^{4}$ switching operations under an applied voltage of a.c. $100 \mathrm{~V}$, a current of $115 \mathrm{~A}$ and a power factor of 0.3 for the specimens internally oxidized in oxygen of $0.1 \mathrm{MPa}$ at $1073 \mathrm{~K}$. The resistance to welding adhesion does not differ from that on the clean contact surface. For the specimens $1000 \mathrm{~T}, 611 \mathrm{~T}$ and $610 \mathrm{~T}$ the resistance to welding adhesion is higher than that of the specimen $\mathrm{CdO}$. For $\mathrm{Ag}-\mathrm{CdO}$ base alloys, even when the oxide particle size becomes finer with the addition of $\mathrm{Ni}$, the resistance to welding adhesion does not improve.

\section{(2) The case in which the arc discharge does not occur}

Figure 5 shows the welding adhesion behavior for the specimens internally oxidized in oxygen of $0.1 \mathrm{MPa}$ at $1123 \mathrm{~K}$. The resistance to welding adhesion decreases with increasing oxide content. This is contrary to the results in the case in which the arc discharge occurs.

\section{(3) Observation of contact surface with a scanning electron microscope}

Photograph 5 shows scanning electron micrographs of the contact surface patterns of the specimens $\mathrm{Ag}$ and 1000T after welding adhesion test under such a condition that the 

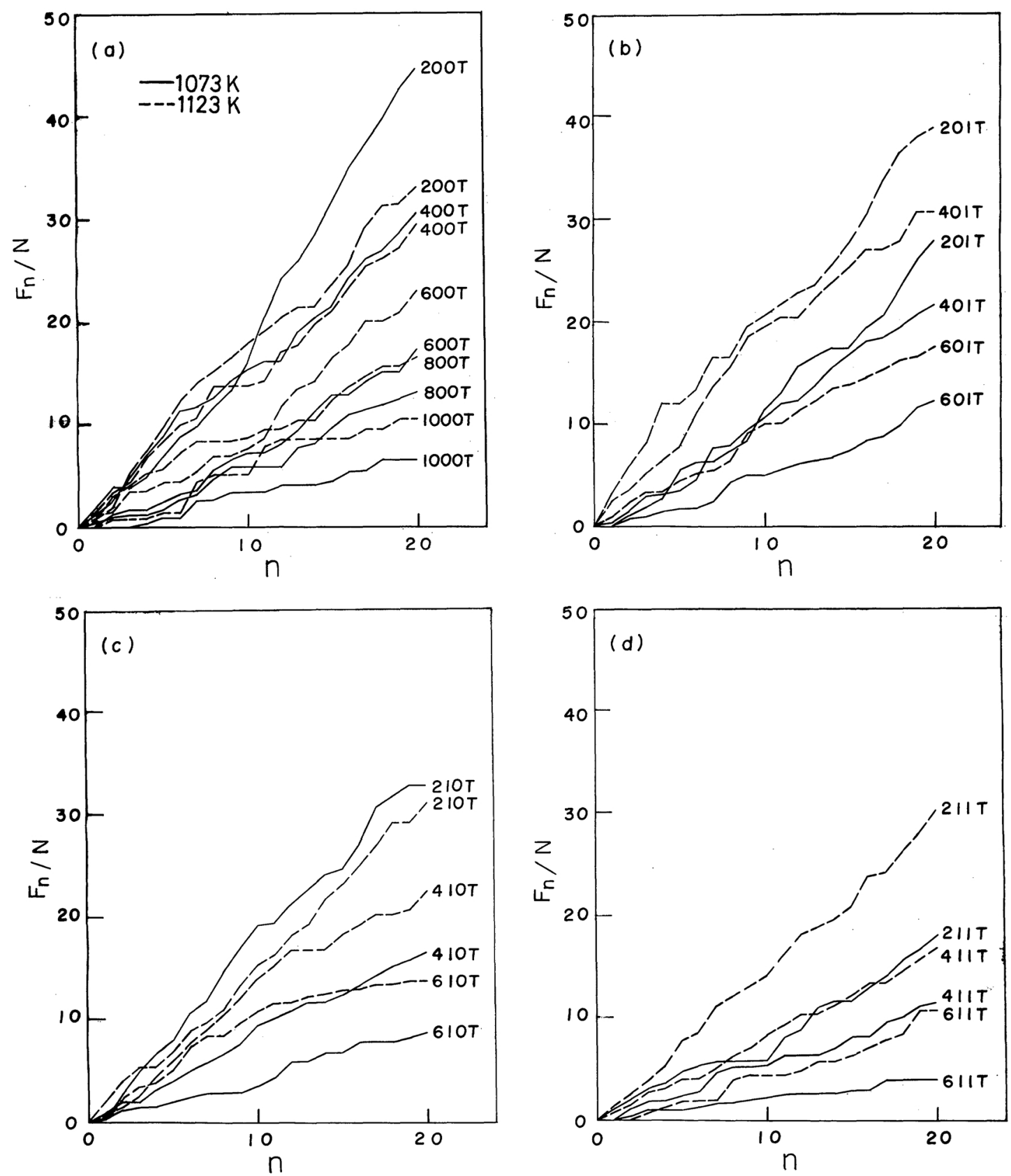

Fig. 1 Relation between cumulative welding force, $F_{n}$, and number of operation, $n$, for specimens internally oxidized in oxygen of $0.1 \mathrm{MPa}$ at 1073 and $1123 \mathrm{~K}$. Testing condition is as shown in Photo. 3. (a) $\mathrm{Ag}-\mathrm{Zn}-\mathrm{Te}$, (b) $\mathrm{Ag}-\mathrm{Zn}-\mathrm{In}-\mathrm{Te}$, (c) $\mathrm{Ag}-\mathrm{Zn}-\mathrm{Sn}-\mathrm{Te}$, and (d) Ag-Zn-Sn-In-Te.

arc discharge occurs. For the specimen Ag the traces showing the occurrence of heavy welding adhesion are found in the center of the contact area. On the other hand, for the specimens dispersing oxide particles, the surface pattern does not remarkably change in all the contact area, and the traces of heavy welding adhesion are not found. Namely, the dispersion of oxide 

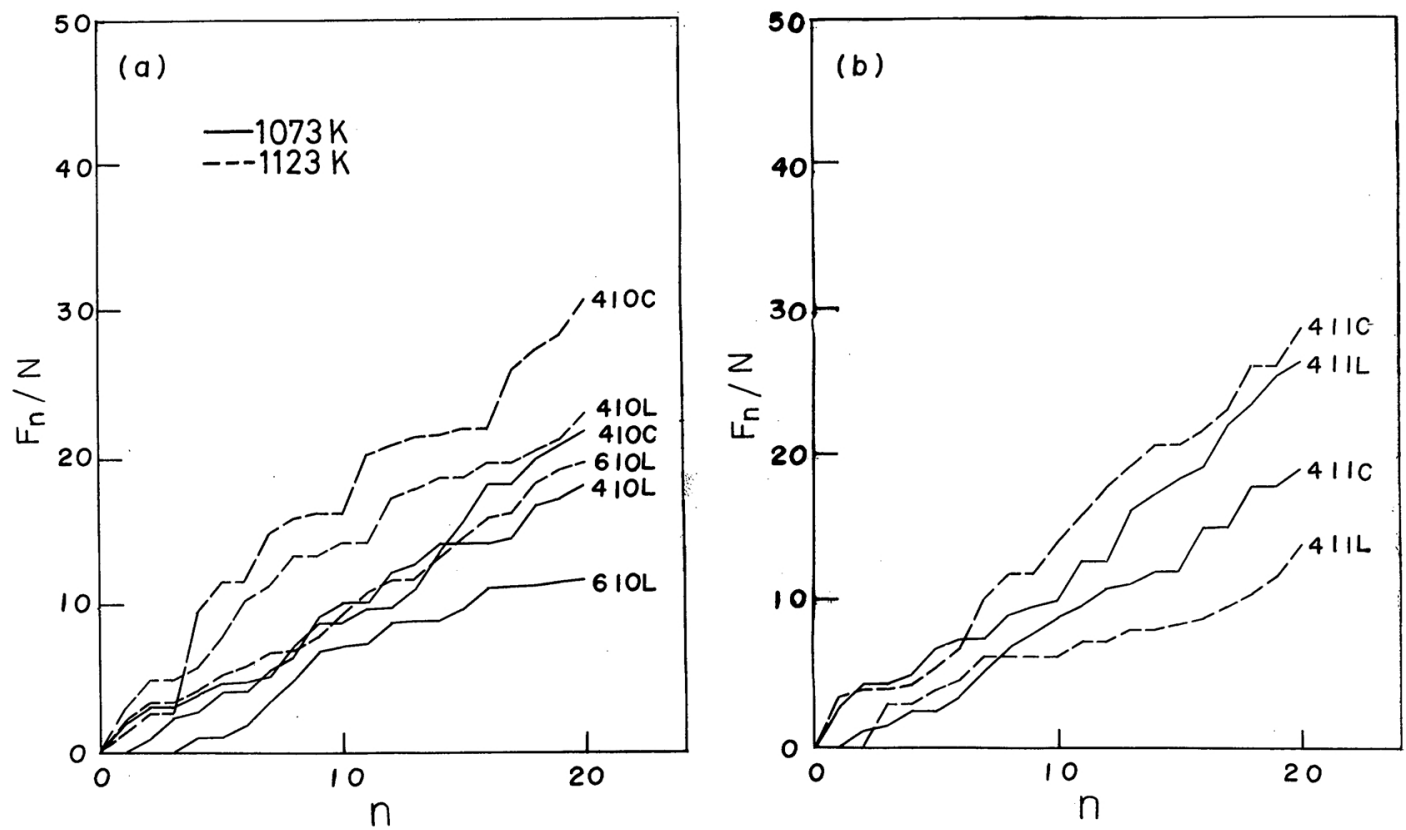

Fig. 2 Relation between cumulative welding force, $F_{n}$, and number of operation, $n$, for specimens internally oxidized in oxygen of $0.1 \mathrm{MPa}$ at 1073 and $1123 \mathrm{~K}$. Testing condition is as shown in Photo. 3.

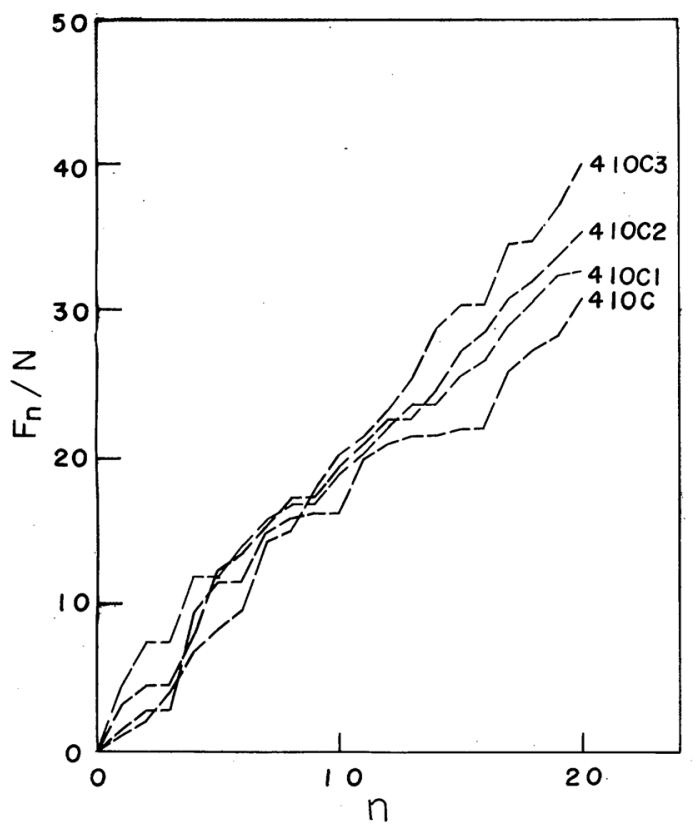

Fig. 3 Relation between cumulative welding force, $F_{n}$, and number of operation, $n$, for specimens internally oxidized in oxygen of $0.1 \mathrm{MPa}$ at $1123 \mathrm{~K}$, Testing condition is as shown in Photo. 3.

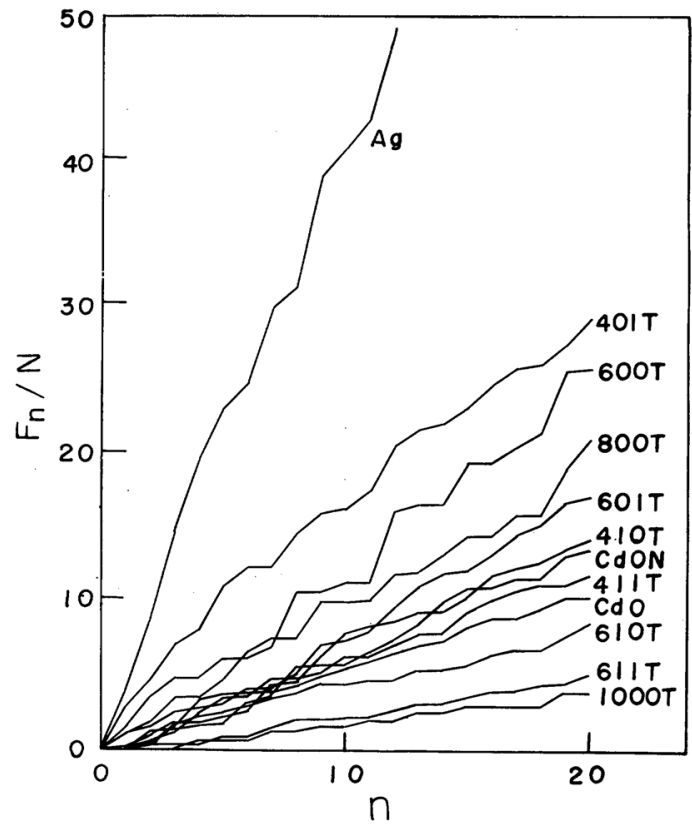

Fig. 4 Relation between cumulative welding force, $F_{n}$, and number of operation, $n$, in contact surface after $3 \times 10^{4}$ switching operations for specimens internally oxidized in oxygen of $0.1 \mathrm{MPa}$ at $1073 \mathrm{~K}$. Testing condition is as shown in Photo. 3, and switching condition is an applied voltage of $100 \mathrm{~V}$, a current of $115 \mathrm{~A}$ and a power factor of 0.3 . 


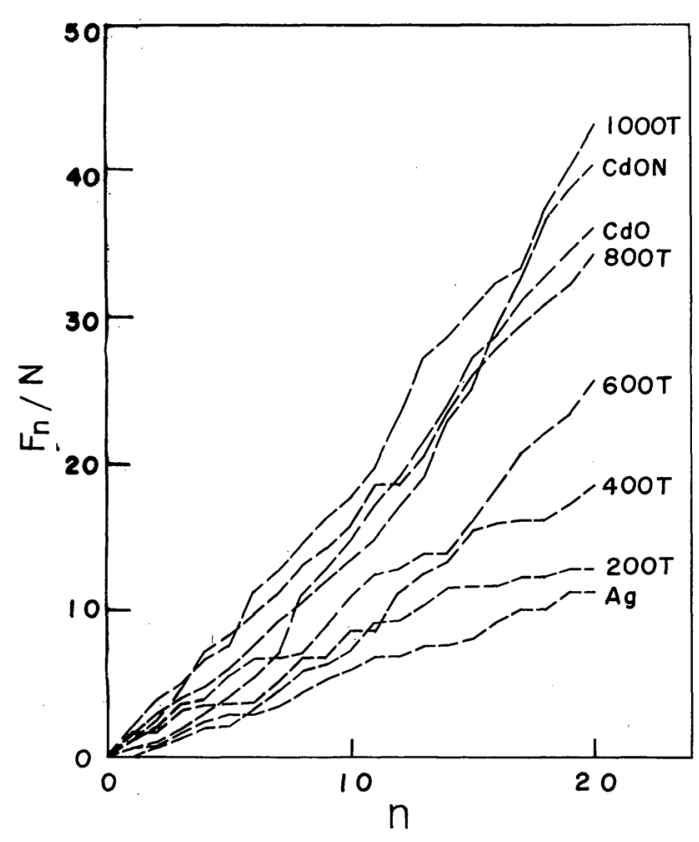

Fig. 5 Relation between cumulative welding force, $F_{n}$, and number of operation, $n$, for specimens internally oxidized in oxygen of $0.1 \mathrm{MPa}$ at $1123 \mathrm{~K}$. Testing condition is as shown in Photo. 4.

particles plays an important role to improve the resistance to welding adhesion.

Photograph 6 shows the contact surface patterns of the specimens $\mathrm{Ag}$ and 1000T after welding adhesion test under such a condition that the arc discharge does not occur. For the specimen Ag the traces of heavy welding adhesion are not found, and the contact area is smaller than that of the specimen 1000T. On the other hand, for the specimens dispersing oxide particles, the contact area is wider, and the oxides of the contact surface are hardly evaporated because the arc discharge does not occur. As the contact surface is covered with oxide layers, the welding adhesion occurs through the oxide layers.

\section{Erosion}

Figure 6 shows the amount of erosion for all the specimens which were tested under an applied voltage of a.c. $100 \mathrm{~V}$, a current of $115 \mathrm{~A}$ and a power factor of 0.3. The amount of erosion in a stationary contact is found to be less than that in a moving contact for all specimens. This difference may be due to the

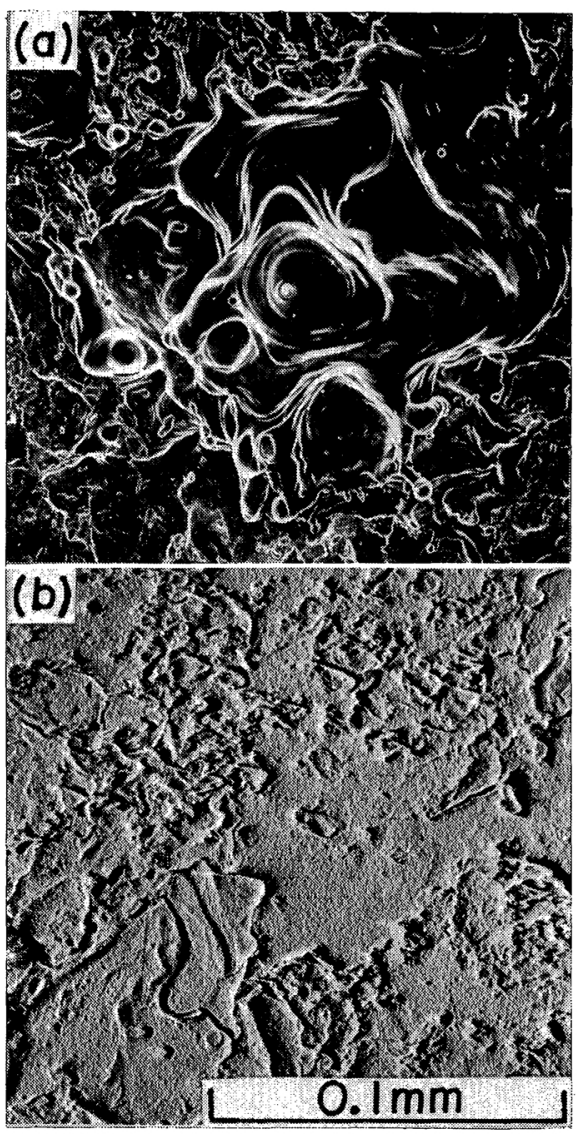

Photo. 5 Scanning electron micrographs of contact surface patterns after welding adhesion test for the specimens (a) Ag and (b) 1000T internally oxidized in oxygen of $0.1 \mathrm{MPa}$ at $1073 \mathrm{~K}$. Testing condition is as shown in Photo. 3.

inertia of the switching contact motion which is directed from a moving contact to a stationary one. The specimen $800 \mathrm{~T}$ has the least amount of erosion in the internally oxidized $\mathrm{Ag}-\mathrm{Zn}-\mathrm{Te}$ alloys. Moreover, the additions of $\mathrm{Sn}$ or $\mathrm{Sn}$ and In are effective to improve the resistance to erosion. The specimens containing $\mathrm{Cu}$ have high resistance to erosion, and the specimen $410 \mathrm{Cl}$ has the least amount of erosion. On the other hand, the specimens containing $\mathrm{Li}$ have low resistance to erosion. For the specimen Ag the amount of erosion is small, but the contact surface is very deformed.

Figure 7 shows the amount of erosion for the specimens having superior resistance to welding adhesion and erosion. Testing con- 


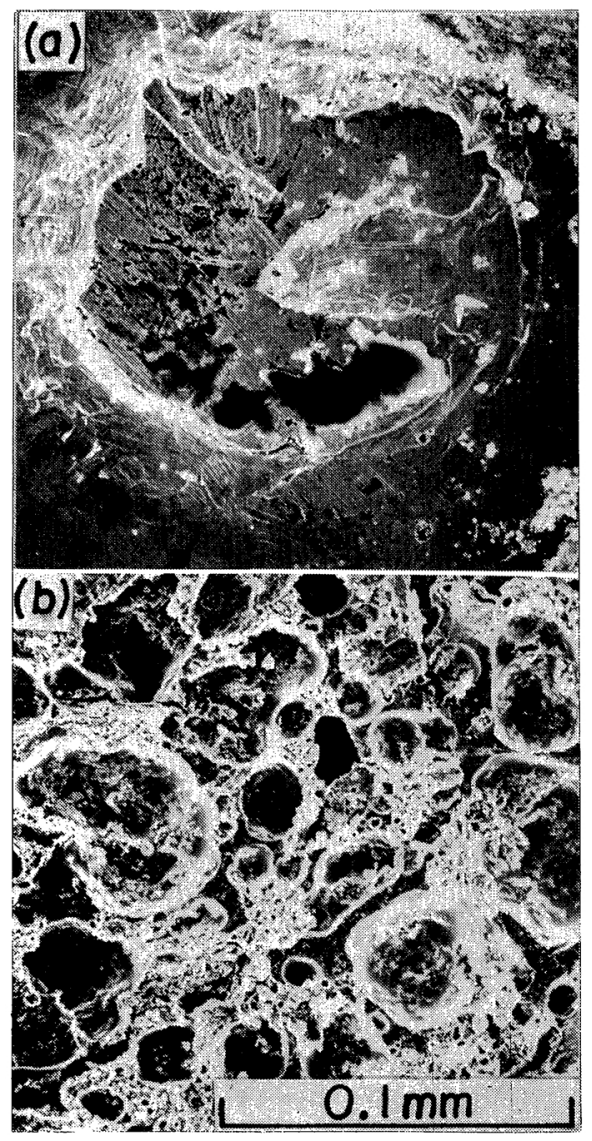

Photo. 6 Scanning electron micrographs of contact surface patterns after welding adhesion test for the specimens (a) $\mathrm{Ag}$ and (b) 1000T internally oxidized in oxygen of $0.1 \mathrm{MPa}$ at $1073 \mathrm{~K}$. Testing condition is as shown in Photo. 4.

dition is an applied voltage of a.c. $200 \mathrm{~V}$, a current of $90 \mathrm{~A}$ and a power factor of 0.28 , and under this condition the reignition occurs. The specimens containing $\mathrm{Sn}$ and In have high resistance to erosion when the reignition occurs.

Figure 8 shows effects of the oxygen pressure and the internal oxidation temperature on erosion. The resistance to erosion scarcely depends on the internal oxidation conditions for all the specimens. It may be due to the fact that the resistance to erosion depends more on the oxide content than on the dispersed structure.

\section{Contact resistance}

Figure 9 shows the contact resistance for the

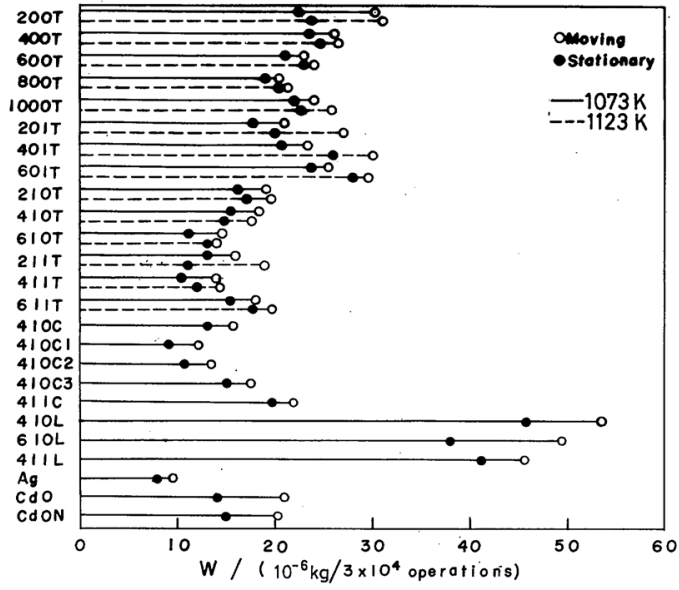

Fig. 6 Amount of erosion, $W$, for specimens internally oxidized in oxygen of $0.1 \mathrm{MPa}$ at 1073 and $1123 \mathrm{~K}$. Applied voltage is $100 \mathrm{~V}$, current is $115 \mathrm{~A}$ and power factor is $\mathbf{0 . 3}$.

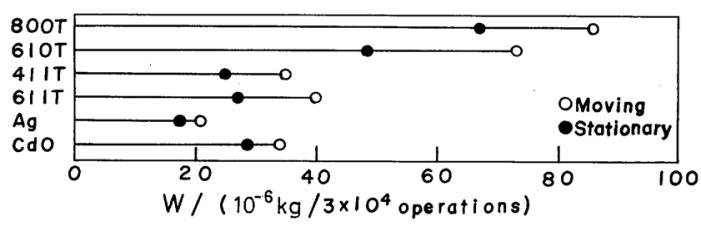

Fig. 7 Amount of erosion, $W$, for specimens internally oxidized in air at $1073 \mathrm{~K}$. Applied voltage is $200 \mathrm{~V}$, current is $90 \mathrm{~A}$ and power factor is 0.28 .

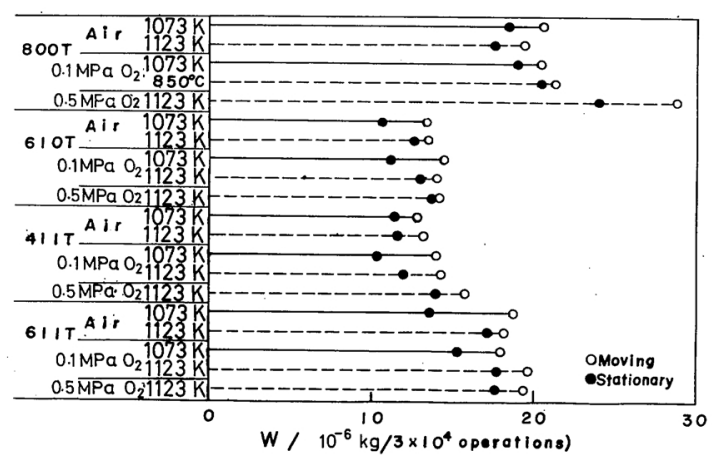

Fig. 8 Amount of erosion, $W$, for specimens internally oxidized in air and in oxygen of 0.1 and 0.5 $\mathrm{MPa}$ at 1073 and $1123 \mathrm{~K}$. Applied voltage is $100 \mathrm{~V}$, current is $115 \mathrm{~A}$ and power factor is $\mathbf{0 . 3}$.

specimens internally oxidized in oxygen of $0.1 \mathrm{MPa}$ at $1073 \mathrm{~K}$, which were tested under an applied voltage of a.c. $100 \mathrm{~V}$, a current of $115 \mathrm{~A}$ and a power factor of 0.3 . The contact resistance tends to increase with increasing 


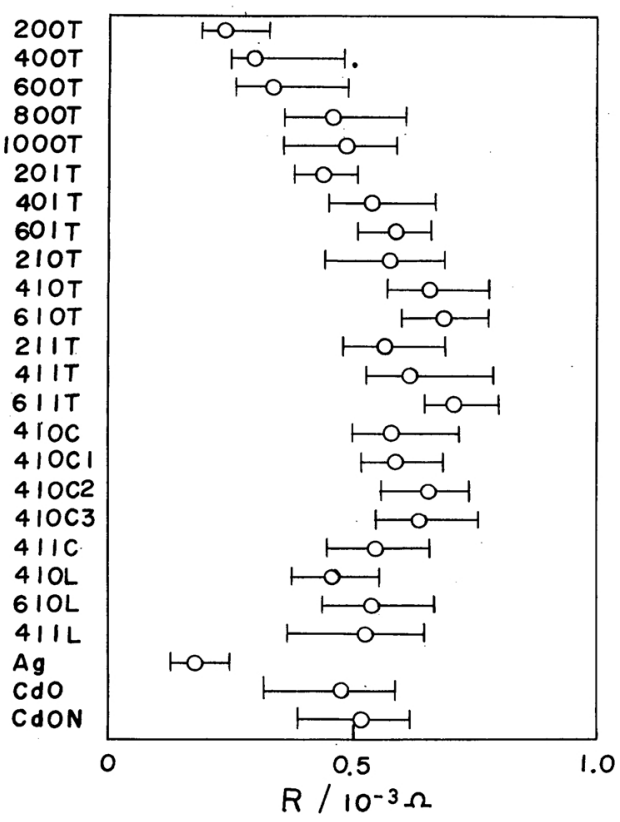

Fig. 9 Contact resistance, $R$, after $3 \times 10^{4}$ switching operations for specimens internally oxidized in oxygen of $0.1 \mathrm{MPa}$ at $1073 \mathrm{~K}$. Applied voltage is $100 \mathrm{~V}$, current is $115 \mathrm{~A}$ and power factor is 0.3 .

oxide content and also with the addition of $\mathrm{Sn}$ and In.

\section{Summary}

$\mathrm{Ag}-\mathrm{Zn}$ alloys containing small amounts of several additional elements such as $\mathrm{Sn}$, In, $\mathrm{Te}, \mathrm{Cu}$ and $\mathrm{Li}$ were internally oxidized. For the specimens in which the oxide particles were uniformly dispersed in the silver matrix, the characteristics of the electrical contact such as the welding adhesion, the erosion and the contact resistance were investigated.

(1) For $\mathrm{Ag}-8-10 \mathrm{Zn}-0.5 \mathrm{Te}, \mathrm{Ag}-6 \mathrm{Zn}-1 \mathrm{Sn}-$ $0.5 \mathrm{Te}$ and $\mathrm{Ag}-4-6 \mathrm{Zn}-1 \mathrm{Sn}-1 \mathrm{In}-0.5 \mathrm{Te}$ alloys internally oxidized in oxygen of $0.1 \mathrm{MPa}$ at $1073 \mathrm{~K}$, the characteristics of the electrical contact are as superior as those of $\mathrm{Ag}-12 \mathrm{CdO}$ alloy.

(2) The resistances to welding adhesion and erosion for internally oxidized $\mathrm{Ag}-\mathrm{Zn}$ base contacts are improved with the additions of $\mathrm{Sn}$ or $\mathrm{Sn}$ and In.

(3) The characteristics of the electrical contact for the specimens with the addition of $\mathrm{Cu}$ or $\mathrm{Li}$, in which the oxide particles are dispersed, are lower than those in the addition of Te.

(4) The resistance to welding adhesion under such a condition that switching arc occurs increases with increasing oxide content, and the most suitable dispersed structure exists for each composition.

(5) The resistance to erosion scarcely depends on the internal oxidation condition, and depends more on the oxide content than on the dispersed structure.

(6) The contact resistance has a tendency to increase with increasing oxide content and also with the addition of Sn and In.

\section{Acknowledgment}

The authors wish to thank Dr. H. Maeda for a critical reading of the manuscript.

\section{REFERENCES}

(1) ASM Committee on Electrical Contact Materials: Metals Handbook, (1955), p. 801.

(2) I. Morimoto, M. Sato and M. Hijikata: J. Japan Inst. Metals, 32 (1968), 597 (in Japanese).

(3) S. Kabayama and E. Kamijo: J. Japan Inst. Metals, 32 (1968), 1204 (in Japanese).

(4) U. Harmsen: Metall, 25 (1971), 133.

(5) U. Harmsen, W. Merl, C. L. Meyer and E. Vinaricky: Z. Metallk., 58 (1967), 752.

(6) E. Vinaricky and U. Harmsen: Metall, 25 (1971), 749.

(7) T. Igarashi, Y. Amano, M. Kume, K. Motoyoshi, T. Nomura and M. Osada: Proc. 8th Intern'l Conf. Electrical Contact Phenomena, Tokyo, (1976), p. 165.

(8) W. Kunert, G. Häußler and H. Scheibe: Proc. 8th Intern'l Conf. Electrical Contact Phenomena, Tokyo, (1976), p. 143.

(9) H. Kimata and S. Nishi: J. Japan Inst. Metals, 35 (1971), 615 (in Japanese).

(10) M. Sato, M. Hijikata and I. Morimoto: J. Japan Inst. Metals, 36 (1972), 410, 765, and 770 (in Japanese).

(11) O. Michikami and S. Yamamoto: J. Japan Inst. Metals, 41 (1977), 551 (in Japanese).

(12) M. Iida: Proc. 8th Intern'l Conf. Electrical Contact Phenomena, Tokyo, (1976), p. 347.

(13) M. Poniatowski, K. H. Schröder and E. D. Schulz: Proc. 8th Intern'l Conf. Electrical Contact Phenomena, Tokyo, (1976), p. 353.

(14) M. Poniatowski, E. D. Schulz and A. Wirths: Proc. 8th Intern'l Conf. Electrical Contact Phenomena, Tokyo, (1976), p. 359.

(15) M. Kume and A. Fukui: Proc. 8th Intern'l Conf. Electrical Contact Phenomena, Tokyo, (1976), 

p. 639.

(16) M. Sato, M. Hijikata and I. Morimoto: Proc. 8th Intern'l Conf. Electrical Contact Phenomena, Tokyo, (1976), p. 19.

(17) M. Sato and M. Hijikata: J. Japan Inst. Metals, 43 (1979), 1095 (in Japanese).

(18) X. Degot: Proc. Third Intern'l Res. Symp. Electric Contact Phenomena, (1966), p. 227.

(19) M. Kume and S. Kabayama: Proc. 7th Intern'l Conf. Electrical Contact Phenomena, (1974), p. 132.

(20) M. Sato, M. Hijikata and I. Morimoto: J. Japan Inst. Metals, 34 (1970), 1067 (in Japanese).
(21) Y. Kaneko: Proc. Intern'l Conf. Electromagnetic Relays, (1963), p. 41.

(22) T. Aida and A. Morita: Proc. 8th Intern'l Conf. Electrical Contact Phenomena, Tokyo, (1976), p. 603.

(23) T. H. Lee: J. Appl. Phys., 30 (1959), 166; 31 (1960), 924.

(24) S. Ho: Denki Setten to Kaihei Sesshokushi (Electrical Contacts), (1956), p. 21.

(25) K. Ando and M. Hasegawa: Yosetsu Arc Gensho (Arcing Phenomena on Welding), (1962), p. 38. 